KREATIF

Jurnal Ilmiah

Prodi Manajemen Universitas Pamulang
ISSN: 2339-0689 (Print), ISSN 2406-8616 (Online)

Volume 7, No 1 Juni 2019, (Halaman 29-43)

Tersedia online di http://openjournal.unpam.ac.id/index.php/kreatif

\title{
PENGARUH KUALITAS PELAYANAN, DAN DISKON TERHADAP KEPUTUSAN PEMBELIAN PENGGUNA OJEK ON-LINE GOJEK DI KOTA TANGERANG SELATAN
}

\author{
Juhaeri \\ Program Studi Manajemen \\ Universitas Pamulang \\ juhaeri@unpam.ac.id
}

\begin{abstract}
ABSTRAK
Tujuan penelitian ini untuk mengetahui : (1) pengaruh kualitas layanan terhadap keputusan pembelian ojek on-line Gojek online di Kota Tangerang Selatan, (2) pengaruh diskon terhadap keputusan pembelian pengguna ojek on-line Gojek online di Kota Tangerang Selatan, dan (3) pengaruh kualitas layanan, dan diskon, terhadap keputusan pembelian pengguna ojek ojek on- line Gojek online di Kota Tangerang Selatan.

Penelitian ini adalah penelitian survei. Populasi dalam penelitian ini adalah semua pengguna ojek on-line Gojek di Kota Tangerang Selatan. Teknik pengambilan sampel dengan purposive sampling sebanyak 100 responden. Menggunakan kuesioner untuk pengumpulan data yang telah diuji validitas dan reliabilitasnya. Dan teknik analisis data menggunakan regresi berganda.

Hasil penelitian ini menunjukan bahwa : (1) terdapat pengaruh positif antara kualitas pelayanan terhadap keputusan pembelian pengguna ojek online Gojek di Kota Tangerang Selatan, terbukti bahwa nilai $\mathrm{t}$ lebih kecil dari 0,05 . $(0,000<0,05)$ dan $\mathrm{t}$ hitung $1,411>\mathrm{t}$ tabel $1,985(1,411>1,985)$ atau berarti H01 ditolak dan Ha1 diterima, ini menunjukkan bahwa ada pengaruh yang signifikan kualitas layanan terhadap keputusan pembelian. (2) terdapat pengaruh diskon terhadap keputusan pembelian pengguna ojek on-line Gojek di Kota Tangerang Selatan, terbukti dengan nilai t lebih besar dari $0,00(0,237>0,05)$ dan thitung 1,189

$<\mathrm{t}$ tabe 1 1,985 atau berarti $\mathrm{H} 02$ diterima dan Ha2 ditolak, ini menunjukkan bahwa terdapat pengaruh signifikan antara diskon terhadap keputusan pembelian. (3) terdapat pengaruh antara kualitas layanan, dan diskon secara bersama-sama terhadap keputusan pembelian pengguna ojek on-line Gojek online di Kota Tangerang Selatan, terbukti dengan nilai $0,001<0,05$ dan $\mathrm{F}$ hitung 6,942> F tabel 3,090 artinya H03 ditolak dan Ha1 diterima, (x1) kualitas layanan dan (x2) diskon memiliki pengaruh signifikan terhadap (y) keputusan pembelian.
\end{abstract}

Kata kunci: Kualitas Pelayanan, Diskon, Keputusan Pembelian.

\section{ABSTRACT}

This study aims to determine: (1) the effect of service quality on purchasing decisions of Gojek online motorcycle taxi users in South Tangerang City, (2) the influence of discounts on purchasing decisions of Gojek online motorcycle taxi users in South Tangerang City, and (3) influence service quality, and discounts, on purchasing decisions of Gojek online motorcycle taxi users in South Tangerang City.

This research is survey research. The population in this study were all Gojek motorcycle taxi drivers in South Tangerang City. The sampling technique uses purposive sampling with a sample of 100 respondents. Data collection techniques using 
questionnaires that have been tested for validity and reliability. The data analysis technique uses mul tiple regression.

The results of this study indicate that: (1) there is a positive effect on service quality on the purchasing decisions of Gojek online motorcycle taxi users in the City of South Tangerang, it is evident that the value of $t$ is smaller than $0.05 .(0,000<0,05)$ and t count 1,411>t table 1,985 (1,411>1,985) or means that HOI is rejected and Hal is accepted, this indicates that there is a significant effect of service quality on purchasing decisions. (2) there is a positive discount effect on the purchasing decisions of Gojek online motorcycle taxi drivers in South Tangerang City, as evidenced by the value $t$ greater than $0.00(0.237>0.05)$ and t count $1.189<t$ tabe $l 1.985(1,185<$ 1985) or means that $\mathrm{HO} 2$ is accepted and Ha2 is rejected, this indicates that there is no significant effect of the discount on the purchase decision. (3) there are influences on service quality, and joint discounts on purchasing decisions of Gojek online motorcycle taxi users in South Tangerang City, as evidenced by the value $0.001<0.05$ and $F$ count 6.942> F table 3.090 which means HO3 is rejected and Hal is accepted. XI (service quality) and X2 (discount) have a significant influence on purchasing decisions (Y).

Keywords: Service Quality, Discounts, Purchasing Decisions.

\section{PENDAHULUAN}

\section{A. Latar Belakang}

Pertumbuhan teknologi semakin hari terus berkembang, sehingga manusia beradaptasi dan memanfaatkannya untuk memudahkan dalam pekerjaan seharihari. Mulai dari jualan online, transaksi online, bekerja online, bahkan sampai kepada hal yang belum terpikir sekalipun. Hal inilah yang dimanfaatkan oleh beberapa perusahaan untuk mengembangkan usahanya lebih kreatif, dan ini juga dimanfaatkan sehingga munculah ojek yang berbasis on-line. Pada awalnya internet ini dimanfaatkan seseorang untuk jasa pengiriman barang dengan menggunakan ojek, dan semakin berkembangnya teknologi saat ini dengan menggunakan smartphone serta aplikasi yang mudah digunakan. Sampai saat ini hal tersebut dimanfaatkan oleh perusahaan yang manaungi ojek online seperti Gojek.

Pada perkembangannya, teknologi saat ini terdapat layanan aplikasi yang dapat digunakan untuk memesan ojek secara online dan memeakan standar pelayanan. Pada mulanya ojek pangkalan hanya berdasarkan wilayah, biasanya mangkal di perempatan jalan, atau didepan gang masuk. Kemudian pengemudi ojek dari wilayah lain tidak bisa sembarang mengambil penumpang disuatu tempat tanpa izin dari driver (pengendara) ojek di wilayah itu. Untuk menggunakan jasanya pun tidak jarang pengguna harus tawar menawar dengan ojeknya. Saat ini banyak sekali penyedia ojek online seperti: Grab bike, Blu jek, Uber, dll. Ojek online dengan harga bervariasi tergantung jarak dan waktu padat.

Gojek adalah salah satu taksi motor online paling populer di Kota Tangerang Selatan. PT. Gojek Indonesia pendirinya adalah Nadiem Makarim dengan Michaelangelo Moran pada tahun 2011. Melalui aplikasi pada telepon seluler, pengemudi ojek dapat melihat urutan di mana entri dan lokasi pembeli segera ditanggapi, dan pelanggan dapat melihat seberapa jauh posisi para pelanggan. ojek merespons pesanan. Gojek telah beroperasi di wilayah Jabodetabek, Termasuk juga Kota Tangerang Selatan. Gojek bukan hanya transportasi untuk orang, tetapi juga dapat untuk antar barang, paket atau dokumen, sebagai mitra bagi toko online maupun took tradisional yang membutuhkan jasa antar paket pada setiap harinya, bahkan sekarang ada fasilitas baru yaitu jasa layanan antar pesan makanan (Go Food). 
Gojek sekarang menjadi pelopor dalam aplikasi ojek online yang menggunakan smartphone melalui layanan GoRide-nya. Sehingga konsumen dapat dengan mudah dalam memesan ojek hanya dengan apliais yang ada pada smartphonenya, dan kemudian akan dijemput oleh pengemudi yang merespon. Pembayaran akan dilakukan apabila konsumen telah sampai pada tujuan, dan besaran tarif yang ditetapkan bervariasi berdasarkan jarak tempuh dan tarif flat yang diterapkan. Metode pembayarannya sangat mudah bagi konsumen, bisa melalui uang tunai atau saldo yang digunakan. Saat ini ada beberapa perusahaan yang merupakan pesaing GoJek seperti: GrabTaxi, GrabBike, dan BluJek. Perusahaan ini memiliki layanan yang mirip dengan layanan GoJek.

Dalam perkembangannya ojek online banyak bermunculan, sehingga perusahaan ojek online khususnya Gojek dituntut untuk bisa bersaing dengan ojek online lainnya. Setiap perusahaan menginginkan penghasilan yang besar dan pengeluaran yang sekecil-kecilnya dengan harapat dapat menambah pengalokasian dana untuk pengembangan usaha.

Ojek online ini muncul karena banyaknya permintaan konsumen yang membutuhkan transportasi yang mudah dan cepat diakses khususnya dikota besar yang selalu terkena macet seperti di Jakarta. Bogor, Tangerang, dan Bekasi. Nadiem Makarim pendiri Gojek, beliau lulusan dari Harvard Business School. Berbeda denga jasa ojek sebelumnya, kebanyakan mangkal pada sebuah lokasi tertentu, gojek memberikan fasilitas transportasi yang memanjakan konsumennya, dapat dipesan malalui Blackberry messenger, telepon, ban juga e-mail seperti yang ditulis pada situs detik.com tahun 2011. Dalam perkembangannya kini Gojek dapat dipesan melalui aplikasi yang dikembangkan sendiri, yang dapat di instal pada smartphone, aplikasinya dapat diunduh di Google playstore untuk android dan appstore untuk yang IOS.

Pada tahun 2016 ada kasus yang mengejutkan tepatnya pada bulan oktober yaitu demo yang dilakukan oleh para pengemudi Gojek. Dan demo ini menuntut agar pengemudi Gojek dapat memilih pesanan yang masuk dari yang sebelumnya pengemudi tidak dapat memilihnya dan juga ada system yang dianggap dapat mengurangi bonus. Karena system yang ada membuat para driver Gojek menerima pesanan terus menerus dikarenakan server Gojek mengirimkan pesanan tanpa henti untuk mengantar penumpang. Dan kalau mereka menolak pesanan, maka persentase performa mereka akan turun, padahal untuk mendapatkan bonus perfroma minimal 50\%.

Perusahaan harus dapat memberikan kualitas pelayanan yang baik kepada konsumen agar perusahaan tidak ditinggal pergi konsumen dan juga pelanggannya. Kalau perlu perusahaan dapat juga menawarkan diskon kepada konsumen dan pelanggan. Ini didukung oleh penelitian Ugeng Haryoko, yang menemukan pengaruh signifikan antara kualitas layanan pada keputusan pembelian. Ini berarti bahwa jika kualitas layanan ditingkatkan, akan ada peningkatan dalam keputusan pembelian. Dan juga didukung oleh penelitian Indri Kartika D \& Andriani K, yang menemukan pengaruh signifikan antara diskon pada keputusan pembelian.

Dari penjelasan tersebut diatas maka peneliti tertarik melakukan penelitian yang berjudul : "Pengaruh Kualitas Pelayanan, Dan Diskon Terhadap Keputusan Pembelian Pengguna Ojek Online Gojek Di Kota Tangerang Selatan". 


\section{B. Perumusan Masalah}

Berdasarkan penjelasan latar belakang di atas berikut rumusan masalah dalam penelitian ini :

1. Berapa besar pengaruh kualitas pelayanan terhadap keputusan pembelian ?

2. Berapa besar pengaruh diskon terhadap keputusan pembelian?

3. Seberapa besar pengaruh kualitas pelayanan dan diskon terhadap Keputusan Pembelian Pengguna Ojek Online Gojek Di Kota Tangerang Selatan secara bersama-sama?

\section{TINJAUAN PUSTAKA}

\section{A. Kualitas Pelayanan}

Kualitas layanan adalah aktivitas yang dilakukan seseorang kepada pihak lain yang tidak berwujud fisik dan tidak menyebabkan kepemilikan tertentu. Menurut Kotler (2009:

143) "Kualitas layanan merupakan keseluruhan dari suatu jasa/produk layanan untuk memenuhi kebutuhan sehingga dapat memenuhi kebutuhan tersurat maupun tersirat". Menurut Tjiptono (2012: 4) kualitas layanan memiliki dua komponen utama, yaitu layanan yang tidak terlihat atau tidak diketahui keberadaannya dan pemberian layanan yang terlihat atau diketahui. Di mana kualitas layanan meliputi: Bukti Fisik, Keandalan, Daya Tangkap, Jaminan, Empati.

Jadi kualitas layanan merupakan kegiatan yang dilakukan oleh Gojek kepada konsumen, yang tidak berwujud dan tidak pula mengakibatkan kepemilikan. Indikator kualitas layanan meliputi: bukti fisik, keandalan, daya tanggap, jaminan, empati menurut Tjiptono (2012: 4).

\section{B. Diskon}

Menurut Kotler dan Keller (2007: 103), " diskon adalah pemberian potongan apabila konsumen melakukan pembayaran lebih cepat dari yang ditentukan, atau juga pemberian potongan dimusim-musim tertentu". Sedangkan menurut Tjiptono (2008: 166), " Diskon merupakan pemberian potongan dari penjual kepada pembeli karena penghargaan tertentu". Jadi Diskon adalah pemberian potongan kepada pembeli untuk kegiatan yang dianggap menyenangkan oleh penjual, dalam hal ini diskon yang diberikan PT Gojek Indonesia kepada pelanggannya. Indikator diskon yang digunakan menurut Kotler dan Keller (2007:

104) adalah diskon tunai (harga diskon untuk pembeli yang membayar langsung, diskonmusim (diskon yang membuat pembelian di luar musim atau liburan), diskon (diberikan kepada konsumen dari harga resmi) terdaftar).

\section{Keputusan Pembelian}

Pendapat Kotler dan Keller (2009: 188) bahwa : "Keputusan pembelian merupakan sebuah tahap akhir sebagai evaluasi, konsumen yang memilih produk yang disukai". Schifman dan Kanuk (2007: 485) berpendapar bahwa : "Keputusan pembelian adalah "Pilihan alternatif yang diberikan penjual untuk mengambil keputusan konsumen".

Dari penjelasan tersebut, dapat ditarik kesimpulan bahwa keputusan pembelian adalah sebuah tindakan individu untuk membeli atau tidak suatu produk/layanan yang ditawarkan. Jadi keputusan pembelian adalah sebuah tindakan untuk membuat keputusan untuk membeli/menggunakan atau tidak produk atau layanan yang ditawarkan oleh Gojek dalam memperoleh kenyamanan dalam transportasi. Indikator yang digunakan menurut Kotler dan Keller (2009: 
178), yaitu : Pilihan produk, pilihan merek, pilihan dealer, jumlah pembelian, waktu pembelian, metode pembelian.

\section{Kerangka Pemikiran}

Dari beberapa penjelasan teori diatas berikut kerangka berfikir dan juga Variabelvariabel dibawah ini merupakan gambaran variabel $\mathrm{X}$ berhubungan terhadap variabel Y.

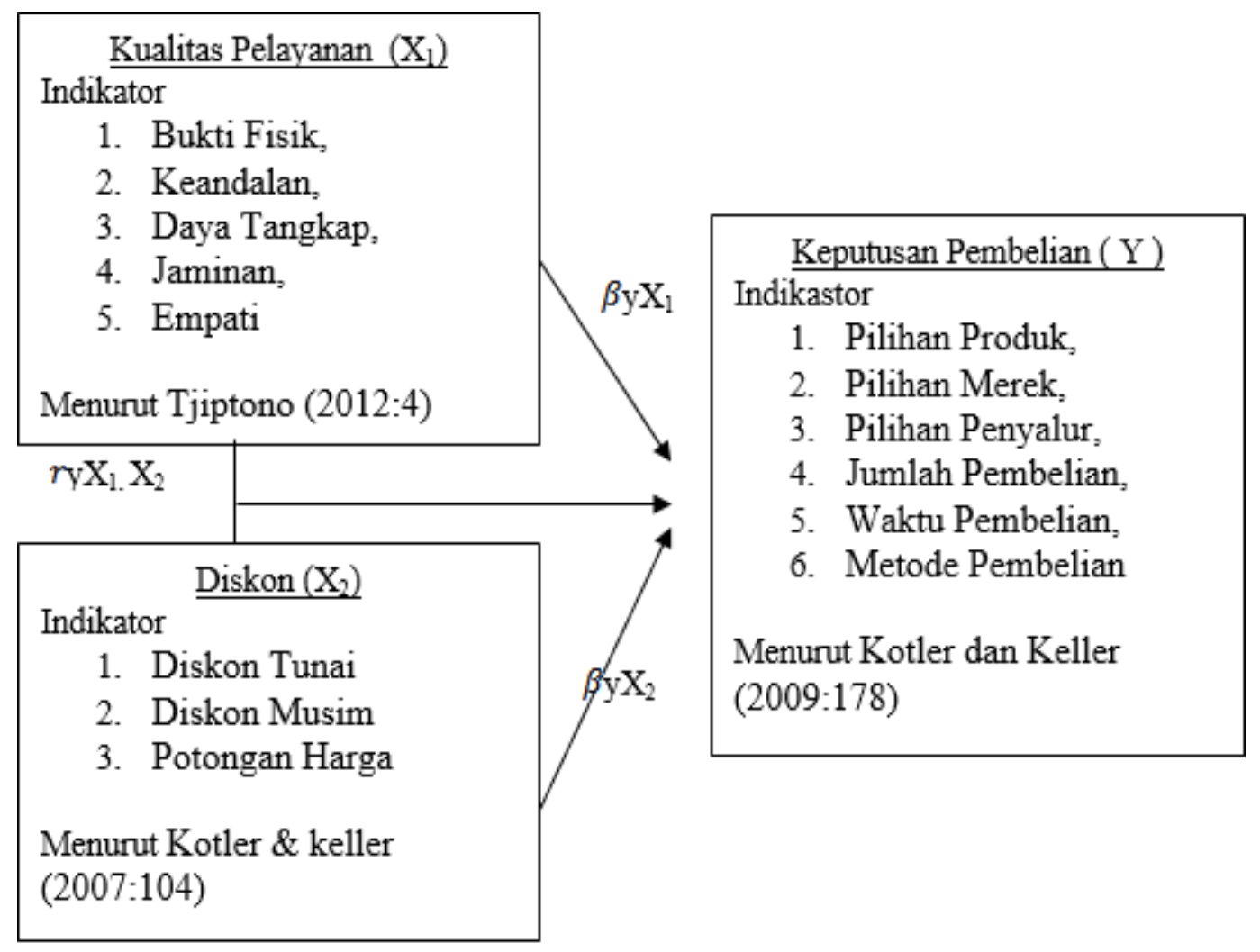

Gambar 1.1

Kerangka Berfikir

\section{E. Hipotesis Penelitian}

Hipotesis penelitian adalah untuk menguji apakah ada pengaruh antara variabel (x), yaitu kualitas layanan, Diskon, dan Keputusan Pembelian. Dapat dijelaskan sebagai berikut: 
1. Kualitas pelayanan

$\mathrm{Hol}_{1}: \beta_{1} \neq 0$ "tidak terdapat pengaruh yang signifikan antara kualitas pelayanan terhadap Keputusan Pembelian"

Hal : $\beta_{1}=0$ "terdapat pengaruh yang signifikan antara kualitas pelayaan terhadap Keputusan Pembelian"

2. Diskon

$\mathrm{Ho}_{2}: \beta_{2} \neq 0$ "tidak terdapat pengaruh yang signifikan antara Diskon terhadap Keputusan Pembelian"

$\mathrm{Ha}_{2}: \beta_{2}=0$ "terdapat pengaruh yang signifikan antara Diskon terhadap Keputusan Pembelian"

3. Kualitas pelayanan dan diskon terhadap keputusan pembelian

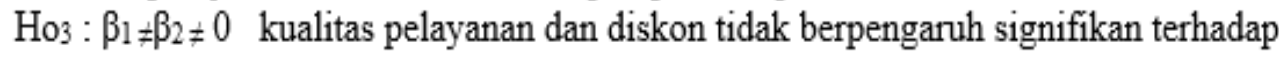
Keputusan Pembelian.

Ha3 : $\beta_{1}=\beta_{2}=0$ kualitas pelayanan dan diskon berpengaruh signifikan terhadap keputusan pembelian.

\section{METODOLOGI PENELITIAN}

\section{A. Tempat dan Waktu Penelitian}

Lokasi pada pengguna PT. Gojek Indonesia Di Kota Tangerang Selatan Adapun waktu yang diperlukan untuk melakukan penelitian ini ialah dari bulan Maret 2019 sampai Mei 2019.

\section{B. Metode Penelitian}

Penelitian yang dilakukan ini bersifat korelasional dimana penelitian tersebut mengamati dua hubungan variabel atau lebih, dan bagaimana variabel itu dinyatakan dalam satu persamaan yaitu koefisien korelasi.

\section{Populasi dan Sampel}

\section{Populasi}

Munurut Sugiyono (2013: 80) populasi merupakan area keseluruhan dari objek atau subjek yang dipelajari penelitia untuk ditarik kesimpulan. Populasi dalam penelitian ini adalah para pengguna Gojek di Kota Tangerang Selatan. Populasi tidak diketahui jumlahnya secara pasti. Sehingga dalam penelitian ini mengambil sampel yang dapat mewakili karakteristik dari populasi.

2. Sampel

Sampel diberikan kepada siapa saja yang ditemui secara acak (random sampling), dan memberikan kesempatan yang sama sebagai sampel menurut Sugiyono (2003: 74), sesuai dengan namanya, sampel yang diambil dilakukan secara acak. Untuk jumlah populasi tidak diketahui :

$$
\begin{aligned}
& n=\frac{Z^{2} \times p(1-p)}{d^{2}} \\
& n=\frac{(3,8416) \times(0,25)}{(0,01)} \\
& n=\frac{(1,96)^{2} \times(0,5)(1-0,5)}{(0,1)^{2}} \\
& n=\frac{0,9604}{0,01} \\
& n=\frac{(3,8416) \times(0,5)(0,5)}{(0,01)} \\
& n=96,04
\end{aligned}
$$


Berdasarkan rumus di atas, diperoleh 96,04, sehingga dibulatkan menjadi 100 responden.

\section{Tehnik Penentuan Data}

Berikut adalah Teknik penentuan data didalam penelitian ini:

1. Data Primer

Yaitu data pengisian kuesioner yang dilakukan pengguna Gojek di Kota Tangerang Selatan, yang bertyujuan untuk mengetahui pengaruh Kualitas Layanan dan diskon terhadap Keputusan Pembelian.

2. Data Sekunder

Yaitu lokasi dan akses informasi dari perusahaan serta beberapa sumber.

\section{E. Metode Analisis Data}

Metode analisis data yang digunakan adalah:

1. Uji Validitas

Uji validitas dalam peneliti ini menggunakan validitas item, dimana teknik product moment untuk mengetahui validitas itemnya, hasil penghitungan validitas instrumen akan dibandingkan dengan $r$ tabel. Dengan ketentuan : a) Apabila $r_{\text {hitung }}$ lebih besar dari pada $r_{\text {tabel }}$ maka valid. b) Dan sebaliknya apabila $r_{\text {hitung }}$ lebih kecil dari pada $r_{\text {tabel }}$ maka tidak valid (pada taraf signifikan 5\%). Dimana syarat minimum $r_{\text {tabel }}$ dalam penelitian ini menggunakan 0,3, Sugiyono (2013:182)

2. Uji Reliabilitas

Uji ini adalah untuk mengukur konsistensi pernyataan kuesioner dari waktu kewaktu. Didalam pegujian reliabilitas, maka hasil reliabilitas (rhitung) akan disesuaikan dengan tabel harga kritis korelasi product moment $(r$ tabel $)$. apabila $r_{\text {hitung }}>r_{\text {tabel }}$ maka instrumen dapat dikatakan reliabel sedangkan syarat minumum untuk $r$ tabel dalam penlitian ini menggunakan 0,6 (Sugiyono, 2013:184)

\section{Uji Asumsi Klasik}

\section{a. Uji Normalitas}

Tes ini dilakukan untuk mengetahui apakah variabel terdistribusi normal atau tidak. Persyaratan untuk mengambil tes Normalitas adalah apabila secara signifikan lebih besar dari a $=5 \%$ maka dapat dikatakan distribusi data normal, Ghozali (2005:105):

(1) Apabila data mengikuti arah garis diagonal atau grafik histogram menunjukkan distribusi normal, maka model regresi memenuhi asumsi normalitas.

(2) Apabila data tidak mengikuti arah garis diagonal atau menjauhi garis, serta grafik histogram tidak menunjukkan distribusi normal, maka model regresi tidak memenuhi asumsi normalitas.

\section{b. Uji Multikolinieritas}

Tes multikolineritas dilakukan dengan cara melihat nilai toleransi dan Variance Inflation Factor (VIF). Tes ini dilakukan untuk mengetahui variabel mana yang menyebabkan multikolinieritas, menurut Ghozali (2005: 92), variabel dikatakan multikolinieritas jika nilai VIF diasumsikan 1 dan angka toleransi mendekati angka 1. Dan batas VIF adalah 10, apabila nilai VIF kurang dari 10, maka tidak terjadi multikolinieritas begitu juga sebaliknya.

\section{c. Uji Heterokedastisitas}


Tes heteroskedastisitas dilakukan untuk menguji apakah model regresi terjadi ketidaksamaan varians residual dari satu pengamatan, yaitu dengan cara melihat grafik plot antara nilai prediksi variabel dependen dan residual menurut Tony Wijaya, (2012: 124). Berikut cara menganalisanya:

(1) Melihat titik-titik apakah membentuk pola teratur bergelombang, apabila itu terjadi menandakan ada masalah heterokedastisitas.

(2) Apabila tidak ada pola tertentu, maka tidak ada masalah heterokedastisitas

\section{Analisis Regresi Linear Berganda}

Ketentuan analisis regresi linier berganda menurut Sugiyono (2010:277) sebagai berikut :

$$
\begin{aligned}
& y=\alpha+\beta_{1} x_{1}+\beta_{2} x_{2}+\varepsilon \\
& \text { dimana: } \\
& \mathrm{y}=\text { Keputusan Pembelian } \\
& \mathrm{x}_{1}=\quad \text { Kualitas Layanan } \\
& \mathrm{x}_{2}=\text { Diskon } \\
& \alpha=\text { konstanta, adalah nilai terkait (y) pada } \\
& \text { saat variabel bebas } 0\left(\mathrm{x}_{1}, \mathrm{x}_{2},=0\right) \\
& \beta_{1}=\quad \text { koefisien regresi berganda antar variabel bebas } \mathrm{x}_{1} \text { terhadap variabel } \\
& \text { terikat } \mathrm{y} \text {, bila variabel bebas } \mathrm{x}_{2} \text {, dianggap konstan } \\
& \beta_{2}=\text { koefisien regresi berganda antar variabel bebas } \mathrm{x}_{2} \text { terhadap variabel } \\
& \text { terikat } \mathrm{y} \text {, bila variabel bebas } \mathrm{x}_{1} \text {, dianggap konstan } \\
& \varepsilon=\text { faktor-faktor lain yang mempengaruhi variabel } \mathrm{y}
\end{aligned}
$$

Model diatas terlihat bahwa variabel terikat (dependen) Y dipengaruhi oleh dua variabel bebas (independent) $\mathrm{x}_{1}, \mathrm{x}_{2}$ yaitu Kualitas Layanan dan Diskon.

5. Rancangan Pengujian Hipotesis
a. Ujit
Digunakan untuk mengetahui besarnya pengaruh antara kualitas layanan dan diskon terhadap keputusan pembelian.
b. Uji F
Digunakan untuk mengetahui besarnya kualitas layanan dan diskon terhadap keputusan pembelian secara bersama-sama. Tes ini dilakukan dengan membandingkan nilai Fhitung dengan nilai Ftable.
c. Uji Koefisien Determinasi
Koefisien determinasi untuk mengetahui kontribusi pengaruh semua variabel|

\section{HASIL DAN PEMBAHASAN}

A. Uji Instrumen Penelitian

1. Hasil Uji Validitas

Berikut adalah hasil dari uji validitas dengan menggunkan SPSS versi 22 : 
Tabel 4.1. Hasil Uji Validitas

\begin{tabular}{|c|c|c|c|c|}
\hline \multicolumn{5}{|c|}{ Hasil Uji Validitas Kualitas Pelayanan } \\
\hline No & Pernyataan & Nilai r hitung & Nilai $\mathrm{r}$ tabel & Hasil \\
\hline 1 & 1 & 0,779 & 0,3 & valid \\
\hline 2 & 2 & 0,680 & 0,3 & Valid \\
\hline 3 & 3 & 0,725 & 0,3 & Valid \\
\hline 4 & 4 & 0,576 & 0,3 & Valid \\
\hline 5 & 5 & 0,761 & 0,3 & Valid \\
\hline 6 & 6 & 0,721 & 0,3 & Valid \\
\hline 7 & 7 & 0,776 & 0,3 & Valid \\
\hline 8 & 8 & 0,619 & 0,3 & Valid \\
\hline 9 & 9 & 0,416 & 0,3 & Valid \\
\hline 10 & 10 & 0,547 & 0,3 & Valid \\
\hline \multicolumn{5}{|c|}{ Hasil Uji Validitas Diskon } \\
\hline 1 & 1 & 0,581 & 0,3 & Valid \\
\hline 2 & 2 & 0,621 & 0,3 & Valid \\
\hline 3 & 3 & 0,732 & 0,3 & Valid \\
\hline 4 & 4 & 0,580 & 0,3 & Valid \\
\hline 5 & 5 & 0,787 & 0,3 & Valid \\
\hline 6 & 6 & 0,350 & 0,3 & Valid \\
\hline \multicolumn{5}{|c|}{ Hasil Uji Validitas Keputusan Pembelian } \\
\hline 1 & 1 & 0,483 & 0,3 & Valid \\
\hline 2 & 2 & 0,724 & 0,3 & Valid \\
\hline 3 & 3 & 0,701 & 0,3 & Valid \\
\hline 4 & 4 & 0,746 & 0,3 & Valid \\
\hline 5 & 5 & 0,631 & 0,3 & Valid \\
\hline 6 & 6 & 0,749 & 0,3 & Valid \\
\hline 7 & 7 & 0,401 & 0,3 & Valid \\
\hline 8 & 8 & 0,763 & 0,3 & Valid \\
\hline 9 & 9 & 0,446 & 0,3 & Valid \\
\hline 10 & 10 & 0,720 & 0,3 & Valid \\
\hline 11 & 11 & 0,650 & 0,3 & Valid \\
\hline 12 & 12 & 0,551 & 0,3 & Valid \\
\hline
\end{tabular}

Dari data diatas terlihat bahwa semua butir pernyataan nilai $r_{\text {hitung }}>r_{\text {tabel }}(0,3)$ Sugiyono (2013:182). Dan dapat dismpulkan untuk semua pernyataan dikatakan valid.

2. Hasil Uji Reliabilitas

Berdasarkan perhitungan yang telah dilakukan menggunkan SPSS terlihat: Dari data diatas terlihat semua item dari pernyataan penelitian ini reliabel, sehingga bisa digunakan sebagai instrument penelitian.

Tabel 4.2. Hasil Uji Reliabilitas

\begin{tabular}{|c|c|c|c|c|}
\hline No & Keterangan & $\begin{array}{c}\text { Cronbach's } \\
\text { Alpha }\end{array}$ & Nilai r tabel & Keterangan \\
\hline 1 & Kualitas Pelayanan & 0,848 & 0,6 & Reliabel \\
\hline 2 & Diskon & 0,820 & 0,6 & Reliabel \\
\hline 3 & Keputusan Pembelian & 0,859 & 0,6 & Reliabel \\
\hline
\end{tabular}

Sumber: Data Primer yang telah diolah.

3. Uji Asumsi Klasik

\section{a. Uji Normalitas Data}

Berdasarkan perhitungan yang telah dilakukan menggunkan SPSS terlihat : 
Tabel 4.3

Hasil Uji Normalitas

One-Sample Kolmogorov-Smirnov Test

\begin{tabular}{|ll|r|}
\hline & & Unstandardized Residual \\
\hline $\mathrm{N}$ & & 100 \\
Normal Parametersa,b & Mean & .0000000 \\
& Std. Deviation & 2.13764308 \\
Most Extreme Differences & .094 \\
& Absolute & .091 \\
& Positive & -.094 \\
& Negative & .942 \\
Test Statistic & & .338 \\
Asymp. Sig. (2-tailed) & & \\
\hline
\end{tabular}

a. Test distribution is Normal.

b. Calculated from data.

c. Lilliefors Significance Correction.

Sumber: Data Primer yang telah diolah

Dari data diatas terlihat nilai Asymp.sig sebesar 0,338 > 0,05, dapat disimpulkan bahwa data terdistribusi secara normal.

Pengujian dalam model regresi ini didistribusikan dalam tes berikut ini:

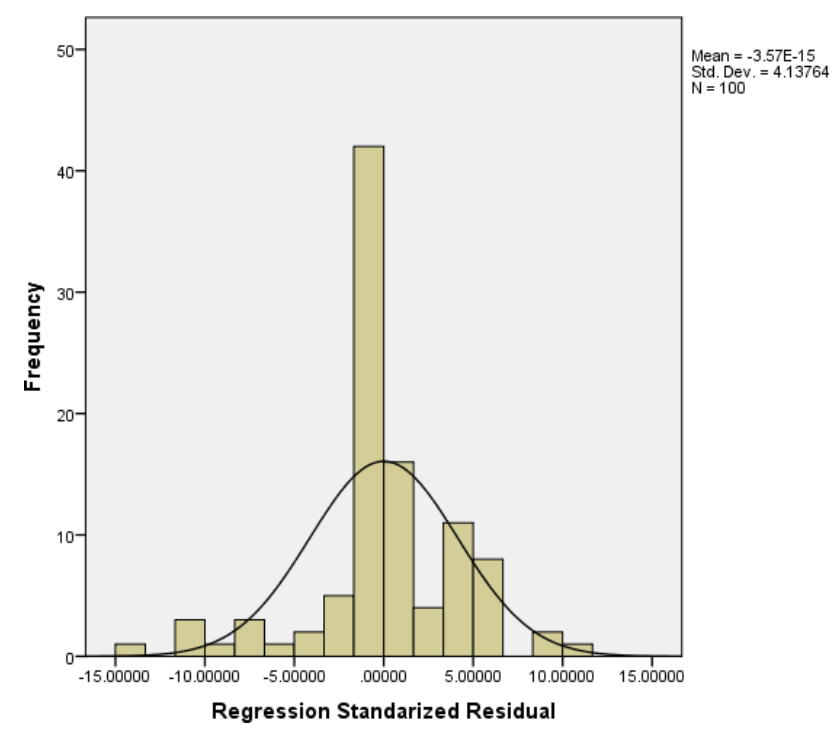

Gambar 4.2

\section{Hasil Uji Normalitasalitas Histogram}

Drai gambar diatas bahwa data yang ada terdistribusi normal, maka data tersebut memenuhi asumsi normal.

b. Uji Multikolinieritas

Berdasarkan pengujian multikolinieritas yang telah dilakukan menggunkan SPSS 
Tabel 4.4

Hasil Uji Multikolinearitas

\begin{tabular}{|ll|r|c|}
\hline \multicolumn{2}{|c|}{ Coefficients $^{\mathrm{a}}$} \\
\cline { 3 - 4 } Model & \multicolumn{2}{c|}{ Collinearity Statistics } \\
\cline { 3 - 4 } & & Tolerance & \multicolumn{1}{c|}{ VIF } \\
\hline 1 & KualitasPelayanan & .984 & 1.016 \\
& Diskon & .984 & 1.016 \\
\hline
\end{tabular}

a. Dependent Variable: KeputusanPembelian Sumber: Data Primer yang telah diolah.

Tabel 4.5

Rangkuman Hasil Uji Multikolearitas

\begin{tabular}{|c|c|c|c|}
\hline Model & Tolerance & VIF & Kesimpulan \\
\hline Kualitas Pelayanan & $0,984>0,10$ & $1,016<10,0$ & Tidak Multikolinearitas \\
\hline Diskon & $0,984>0,10$ & $1,016<10,0$ & Tidak Multikolinearitas \\
\hline
\end{tabular}

terlihat :

Terlihat bahwa nilai toleransi lebih besar dari 0,10 dan nilai VIF lebih kecil dari 10,0 sehingga tidak memiliki masalah multikolinieritas..

\section{c. Uji Heteroskedastisitas}

Tes heroskedastisitas menggunakan program SPSS Versi 22. Grafik Scatter Plot dalam uji heteroskedastisitas sebagai berikut :

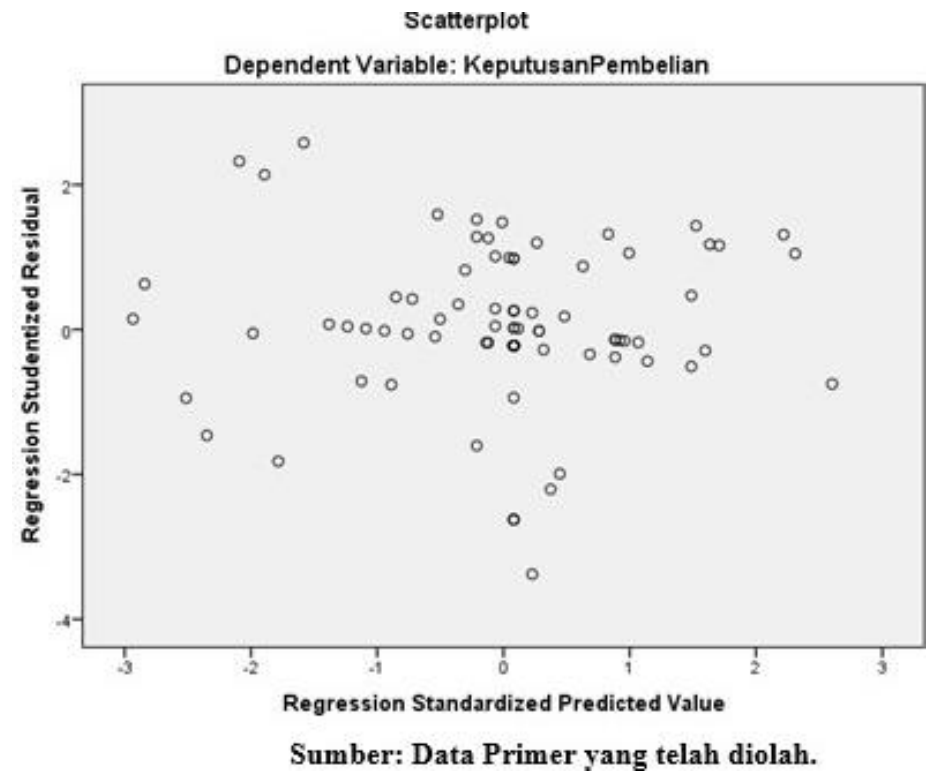

Berdasarkan bagan sebar di atas, terlihat menyebar secara acak titik-titiknya, baik di atas dan di bawah angka 0 pada sumbu Y. Sehingga disimpulkan tidak ada heteroskedastisitas dalam model regresi dalam penelitian ini..

4. Analisis Regresi Linier Berganda

Berdasarkan pengujian regresi linier berganda yang telah dilakukan menggunkan SPSS terlihat : 
Tabel 4.6

Rangkuman Hasil Uji Regresi Linear Berganda

\begin{tabular}{|l|r|r|r|}
\hline \multirow{2}{*}{} & \multicolumn{2}{|c|}{ Coefficients $^{\mathrm{a}}$} & $\begin{array}{c}\text { Standardized } \\
\text { Coefficients }\end{array}$ \\
\cline { 2 - 4 } Model & \multicolumn{1}{|c|}{$\mathrm{B}$} & Std. Error & \multicolumn{1}{c|}{ Beta } \\
\hline 1 (Constant) & 37.419 & 5.817 & .142 \\
KualitasPelayanan & .166 & .118 & .119 \\
\hline \multicolumn{1}{|c|}{ Diskon } & .121 & .102 & \\
\hline
\end{tabular}

a. Dependent Variable: KeputusanPembelian

Sumber: Data Primer yang telah diolah.

Model Regresi yang diperoleh adalah $\mathrm{Y}=37,419+0,166 \mathrm{X}_{1}+0,121 \mathrm{X}_{2}+\mathrm{e}$

a. Nilai konstanta sebesar 37,419 artinya walaupun tanpa variable kualitas pelayanan dan diskon nilai keputusan pembelian tetap ada yaitu 37,419.

b. Variabel kualitas layanan (x1) memiliki pengaruh positif terhadap keputusan pembelian (y) dengan koefisien 0,166, yang berarti bahwa jika variabel kualitas layanan (x1) meningkat satu satuan dengan asumsi variabel $(x 2)$ tetap, keputusan pembelian (y) akan meningkat sebesar 0,166, sehingga besarnya pengaruh kualitas layanan terhadap keputusan pembelian adalah $16,6 \%$.

c. Variabel diskon ( $\mathrm{x} 2)$ memiliki pengaruh positif pada keputusan pembelian (y) dengan koefisien 0,121 yang berarti bahwa jika variabel diskon (x2) meningkat satu unit dengan asumsi kualitas layanan (x1) tetap, variabel, keputusan pembelian (y) akan meningkat sebesar 0,121. Sehingga pengaruh diskon terhadap keputusan pembelian adalah $12,1 \%$.

5. Uji Hipotesis Parsial (Uji T)

Berdasarkan perhitungan menggunakan SPSS versi 2.2 yang diperoleh oleh thitung untuk variabel independen, diferensiasi kompetitif, kualitas layanan, diskon pada keputusan pembelian, sebagai berikut :

Tabel 4.7

\section{Rangkuman Hasil Uji $\mathbf{T}_{\text {hitung }}$}

\begin{tabular}{|c|c|c|c|c|c|c|}
\hline \multicolumn{7}{|c|}{ Coefficients $^{\mathrm{a}}$} \\
\hline \multirow{2}{*}{\multicolumn{2}{|c|}{ Model }} & \multicolumn{2}{|c|}{ Unstandardized Coefficients } & \multirow{2}{*}{$\begin{array}{c}\text { Standardized } \\
\text { Coefficients } \\
\text { Beta }\end{array}$} & \multirow[b]{2}{*}{$t$} & \multirow[b]{2}{*}{ Sig. } \\
\hline & & B & Std. Error & & & \\
\hline \multirow[t]{3}{*}{1} & (Constant) & 37.419 & 5.817 & & 6.433 & .000 \\
\hline & KualitasPelayanan & .166 & .118 & .142 & 1.991 & .162 \\
\hline & Diskon & .121 & .102 & .119 & 1.989 & .237 \\
\hline
\end{tabular}

a. Dependent Variable: KeputusanPembelian Sumber: Data Primer yang telah diolah. 


\section{a. Pengujian Hipotesis Pertama}

$\mathrm{Hol}_{1}: \beta_{1} \neq 0$ "tidak terdapat pengaruh yang signifikan antara kualitas pelayanan terhadap keputusan pembelian"

$\mathrm{Ha}_{1}: \beta_{1}=0$ "terdapat pengaruh yang signifikan antara kualitas pelayanan terhadap keputusan pembelian"

Dari tabel 4.7 diatas dapat dilihat bahwa variabel kualitas pelayanan diperoleh signifikansi $\mathrm{t}<$ dari 0,05 dan $\mathrm{t}$ hitung $1,991>\mathrm{t}_{\text {tabel }}$ sebesar 1,985 atau berarti $\mathrm{H}_{01}$ ditolak dan $\mathrm{H}_{\mathrm{al}}$ diterima, hal ini menunjukan bahwa terdapat pengaruh yang signifikan antara kualitas pelayanan terhadap keputusan pembelian.

\section{b. Pengujian Hipotesis Kedua}

$\mathrm{Ho}_{2}: \beta_{2} \neq 0$ "tidak terdapat pengaruh yang signifikan antara diskon terhadap keputusan pembelian"

$\mathrm{Ha}_{2}: \beta_{2}=0$ "terdapat pengaruh yang signifikan antara diskon terhadap keputusan pembelian"

Dari tabel 4.7 diatas dapat dilihat bahwa variabel diskon diperoleh signifikansi $\mathrm{t}>0,00$ yaitu $0,237>0,05$ dan $\mathrm{t}$ hitung $1,989>\mathrm{t}$ tabel sebesar 1,985 , yang berarti $\mathrm{H}_{\mathrm{a} 2}$ diterima dan $\mathrm{Ho}_{2}$ ditolak, hal ini menunjukan bahwa terdapat pengaruh signifikan antara diskon terhadap keputusan pembelian.

6. Uji Hipotesis Simultan (Uji F)

Hasil uji F menggunakan SPSS di dapat :

Tabel 4.8

Rangkuman Hasil Uji Annova

\begin{tabular}{|rl|r|r|r|r|r|}
\hline \multicolumn{1}{|l|}{} & Sum of Squares & \multicolumn{1}{|c|}{ df } & Mean Square & \multicolumn{1}{c|}{ F } & \multicolumn{1}{c|}{ Sig. } \\
\hline 1 & Regression & 67.861 & 2 & 33.931 & 6.942 & $.149^{\mathrm{b}}$ \\
& Residual & 1694.889 & 97 & 17.473 & & \\
& Total & 1762.750 & 99 & & & \\
\hline
\end{tabular}

a. Dependent Variable: KeputusanPembelian

b. Predictors: (Constant), Diskon, KualitasPelayanan

Sumber: Data Primer yang telah diolahs

$\mathrm{Ho}_{3}: \beta_{1} \neq \beta_{2} \neq 0$ kualitas pelayanan dan diskon tidak berpengaruh signifikan terhadap keputusan pembelian.

$\mathrm{Ha}_{3}: \beta_{1}=\beta_{2}=0$ kualitas pelayanan dan diskon berpengaruh signifikan terhadap keputusan pembelian $Y$.

Dari hasil uji anova diatas diperoleh nilai signifikansi $0,001<0,05$ dan $\mathrm{F}$ hitung $6,942>\mathrm{F}$ tabel 3,090 berarti $\mathrm{H}_{03}$ ditolak dan $\mathrm{H}_{2}$ diterima, maka dengan demikian kualitas pelayanan dan diskon berpengaruh signifikan terhadap keputusan pembelian.

7. Koefisien Dterminasi 
Untuk mencari koefisiensi determinasi, caranya adalah dengan dengan mengkuadratkan hasil korelasi kemudian dikalikan dengan angka 100\%.

Tabel 4.9

Rangkuman hasil uji koefisein determinasi

Model Summary ${ }^{\text {b }}$

\begin{tabular}{|l|r|r|r|r|r|}
\hline Model & \multicolumn{1}{|c|}{ R } & R Square & \multicolumn{1}{c|}{$\begin{array}{c}\text { Adjusted R } \\
\text { Square }\end{array}$} & $\begin{array}{c}\text { Std. Error of the } \\
\text { Estimate }\end{array}$ & Durbin-Watson \\
\hline 1 & $.196^{\mathrm{a}}$ & .138 & .019 & 4.18008 & 1.062 \\
\hline
\end{tabular}

a. Predictors: (Constant), diskon, KualitasPelayanan

b. Dependent Variable: KeputusanPembelian

sumber: data primer yang telah diolah.

Berdasarkan hasil perhitungan diperoleh koefisien determinasi sebesar 0,138. Ini berarti kontribusi yang diberikan oleh kualitas layanan dan diskon terhadap keputusan pembelian adalah 13,8\% sedangkan sisanya 86,2\% dipengaruhi oleh variabel lain yang tidak diteliti, seperti: harga, lokasi, promosi dan sumber daya manusia, dll.

\section{KESIMPULAN}

Dari penjelasan diatas peneliti menyimpulkan sebagai berikut :

1. Menujukan bahwa variabel kualitas pelayanan berpengaruh signifikan terhadap keputusan pembelian, terlihat bahwa pengguna ojek online gojek di Kota Tangerang Selatan merasa nyaman, serta driver sopan dalam melayani konsumen. Semakin baik kualitas pelayanan yang diberikan baik aplikasi maupun driver maka akan meningkatkan daya beli konsumen terhadap jasa transportasi. Hal ini merupakan strategi yang harus dipertahankan oleh PT Gojek.

2. Kesmpulan yang kedua menujukan bahwa variable diskon berpengaruh signifikan terhadap keputusan pembelian, sebab Gojek merupakan jasa trasportasi yang memberikan informasi yang lengkap terkait produk dengan harga diskon yang sedang ditawarkan melalui aplikasi maupun website. Dengan demikian apabila diskon diberikan maka akan mampu meningkatkan daya beli konsumen untuk menggunakan jasa transportasi Gojek.

3. Besarnya pengaruh kulitas pelayanan dan diskon terhadap keputusan pembelian adalah sebesar $13,8 \%$ sedangkan sisanya sebesar $86,2 \%$ dipengaruhi oleh faktor lain yang tidak di teliti, misalnya harga, lokasi, promosi, sumberdaya manusia, dll.

\section{SARAN}

Berikut adalah saran yang dapat penelitia sampaikan dari pembahasan diatas :

1. Berdasarkan hasil olah data dan penyebaran kuisioner maka sebaiknya pihak Gojek sendiri harus lebih memperhatikan kualitas pelayanan terutama pada Driver agar selalu bersikap sopan santun dalam melayani pelanggan. Karena dari hasil penelitian ini hal tersebut menadapat respon yang kurang baik

2. Dari hasil penyebaran dan olah data kuisioner maka masih terhadap konsumen mengeluh tentang potongan harga. Ternyata konsumen lebih senang kalau Gojek sering memberikan potongan harga.

3. Berdasarkan hasil penelitian yang di lakukan konsumen jarang menggunakan 
Gojek dihari libur. Ini mungkin bisa dijadikan bahan pertimbangan strategi Gojek untuk menigkatkan strategi yang pas dihari libur, agar konsumen tetap konsisten menggunakan jasanya.

\section{DAFTAR PUSTAKA}

Alma, Buchori. (2010). Manajemen Pemasaran dan Pemasaran Jasa". Bandung : Penerbit Alfabeta.

Gani, I. \& Amalia, S. (2015). Alat Analisis Data: Aplikasi Statistik untuk Penelitian Bidang Ekonomi dan Sosial. Yogyakarta: Andi

Hasibuan, Malayu S.P. (2014). Manajemen Sumber Daya Manusia. Jakarta : PT. Bumi Aksara

Kotler, Philip., Kevin Lane, Keller. (2007). Manajemen Pemasaran: Edisi 12 Belas Jilid 2. Diterjemahkan oleh Benyamin Molen. Jakarta: PT. INDEKS

Kristo, F. (2015). Anthony Tan, Pria Kaya Malaysia Pencipta Ojek GrabBike. Detik.com.

http://inet.detik.com/cyberlife/d3008049/anthonytanpriakayamalaysiapencipta ojekgrabbike.

Leli. (2016). Berita Hari Ini: Ribuan Driver Gojek Mogok dan Gelar Demo Tuntut Tarif Normal Dikembalikan. Newsth. http://www.newsth.com/ruptik/24054/ beritahariiniribuandrivergojekmogokdangelardemotuntuttarifnormaldikembali kan/

Liputan6.com. (2016). Penurunan Tarif Selalu Jadi Biang Kerok Demo GrabBike dan Go-Jek. http://tekno.liputan6.com/read/2680391/penurunantarifselalu jadibiangkerokdemograbbikedangojek (v)

Nistanto, R. K. (2016). Uber Resmi Gelar Layanan Ojek Motor di Jakarta. Kompas.com. http://tekno.kompas.com/read/ 2016/04/13/ 08240077/Uber .Resmi .Gelar.Layanan.Ojek.Motor.di.Jakarta

Saladin, Djaslim. (2007). Intisari Pemasaran dan Unsur-unsur Pemasaran, Edisi 4. Bandung: Penerbit Linda Karya.

Sugiyono. (2013). Metode Penelitian Bisnis. Bandung: Penerbit CV Alfabeta. 